\title{
Burkitt lymphoma presenting as multifocal doughnut-shaped masses in the stomach of a patient with AIDS
}

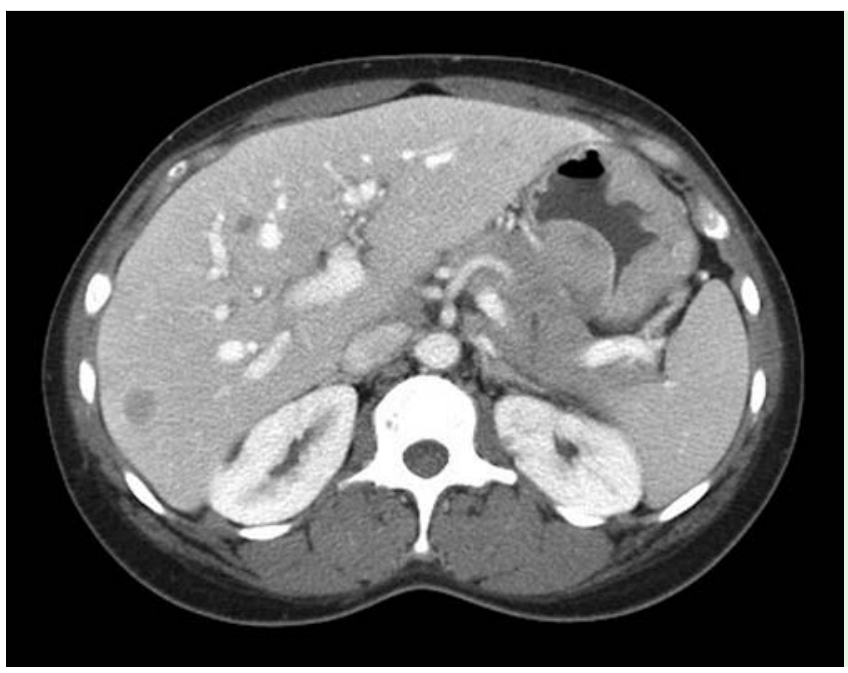

Fig. 1 Abdominal computed tomography (CT) scan showing gastric wall thickening and a non-enhancing hepatic lesion.

A 46-year-old man presented with a 1-month history of epigastric pain. His medical history was significant for human immunodeficiency virus (HIV) infection but he was not on treatment for this. His physical examination and initial blood test results were unremarkable, other than the finding of a CD4 count of $198 / \mu \mathrm{L}$ and a viral load of 370000 copies/mL.

An oral and intravenous contrast-enhanced computed tomography (CT) scan of the abdomen showed an ulcerated and thickened posterior gastric wall and multiple liver lesions suspicious of metastatic gastric adenocarcinoma ( Fig.1). An esophagogastroduodenscopy (EGD) was performed and showed multiple ulcerated doughnut-shaped masses of $1-3 \mathrm{~cm}$ in size in the gastric body and fundus ( $\bullet$ Fig.2). Endoscopic ultrasound (EUS) revealed multiple heterogeneous liver masses up to $3 \mathrm{~cm}$ in size.

Forceps biopsy of the gastric masses and EUS-guided core biopsy of a liver lesion revealed diffuse proliferation of lymphocytes with round nuclei, scant cytoplasm, and numerous tangible body macrophages, which imparted a starry-sky appearance ( Fig.3a,b). The neoplastic lymphoid cells were positive with immu- nohistochemical staining for the $\mathrm{CD} 20$ ( Fig. 3c), CD10, and BCL6 (B-cell lymphoma 6) proteins ( Fig.3d) but were negative for the BCL2 antigen. The proliferative activity, as determined by a Ki-67 immunostain, was nearly $100 \%$. Fluorescence in situ hybridization was positive for the MYC/IGH fusion and negative for the BCL2 rearrangement. These findings were diagnostic of Burkitt lymphoma. Lymphoma can be classified into Hodgkin and non-Hodgkin types, with the latter being the type more commonly found in the gastrointestinal tract. The stomach is the most frequently involved organ and accounts for $60 \%-75 \%$ of all gastrointestinal lymphomas, which are usually diffuse large B cell lymphomas or extranodal marginal zone lymphomas of mucosaassociated lymphoid tissue (MALT) lymphomas [1].

The gastrointestinal tract is a common site of involvement by Burkitt lymphoma in pediatric and HIV-positive populations and should be considered in the differential diagnosis [2-4]. The majority of HIVpositive patients diagnosed with Burkitt lymphoma present with disseminated disease and are treated with intensive immunochemotherapy [5].

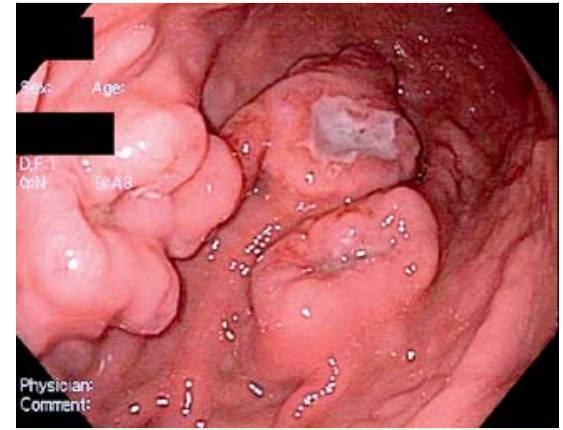

Fig. 2 Multiple ulcerated doughnut-shaped masses seen on endoscopy in the body and fundus of the stomach.

Endoscopy_UCTN_Code_CCL_1AB_2AD_3AB

Competing interests: None

\section{Michael Sai Lai Sey', Magdalena Czader $^{2}$, John M. DeWitt ${ }^{3}$}

${ }^{1}$ Division of Gastroenterology and Hepatology, Western University, London, Ontario, Canada

${ }^{2}$ Department of Pathology and Laboratory Medicine, Indiana University Medical Center, Indianapolis, Indiana, USA

${ }^{3}$ Division of Gastroenterology and Hepatology, Indiana University Medical Center, Indianapolis, Indiana, USA

\section{References}

1 Ghimire $P, W u G Y$, Zhu L. Primary gastrointestinal lymphoma. World J Gastroenterol 2011; 17: 697-707

2 Guarner J, del Rio C, Carr D et al. Non-Hodgkin's lymphomas in patients with human immunodeficiency virus infection. Presence of Epstein-Barr virus by in situ hybridization, clinical presentation, and follow-up. Cancer 1991; 68: 2460-2465 

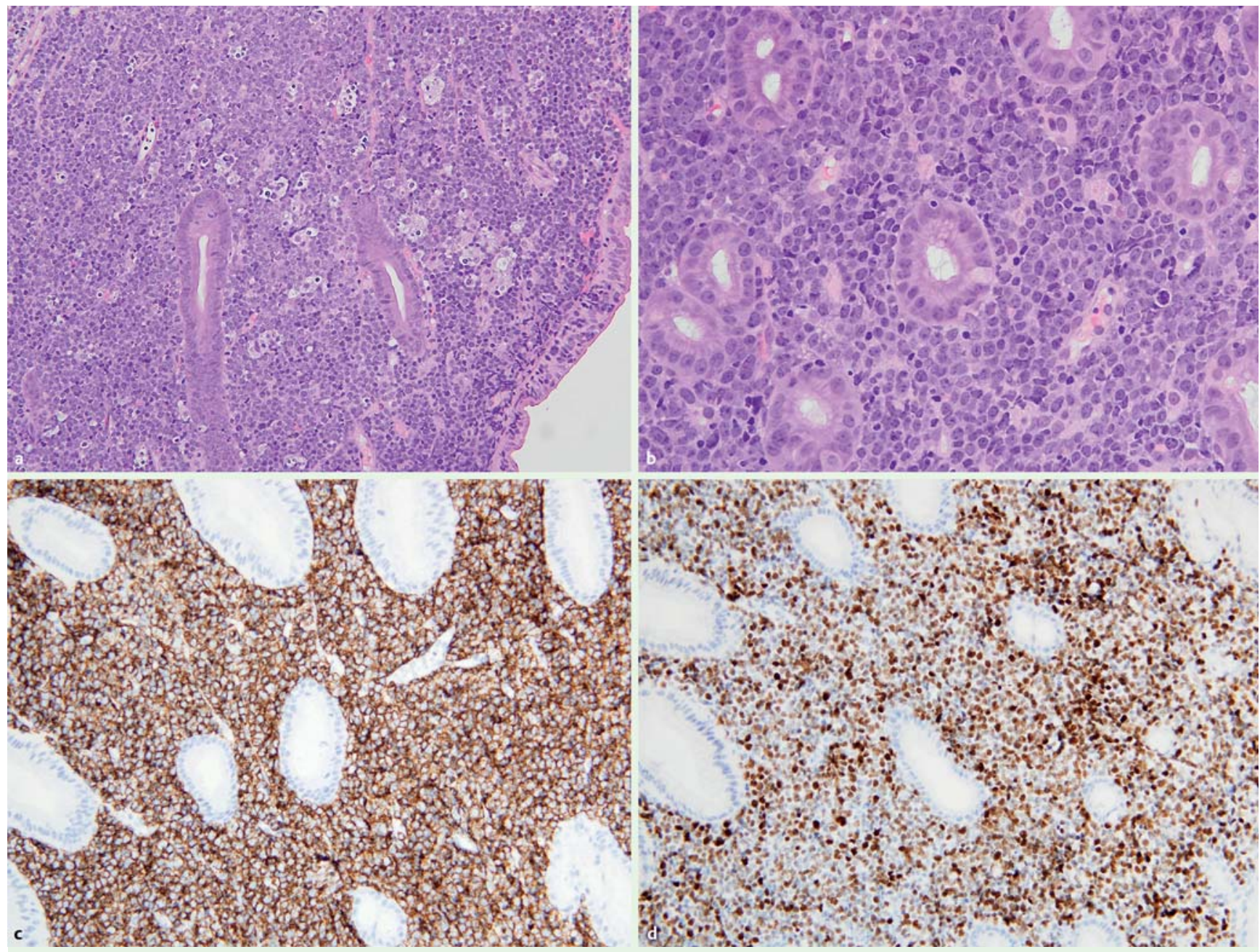

Fig. 3 Morphologic and immunohistochemical features of Burkitt lymphoma as illustrated by: a an extensive diffuse lymphoid proliferation with the classic starry-sky pattern; b neoplastic lymphoid cells that are medium sized with predominantly round nuclei, inconspicuous nucleoli, and scant cytoplasm; c strong immunoreactivity with a CD20 immunostain; $\mathbf{d}$ positivity of the neoplastic lymphoid cells with the BCL6 immunostain.

3 Liou JM, Wang HP, Ko BS et al. Images of interest. Gastrointestinal: Burkitt's lymphoma. J Gastroenterol Hepatol 2005; 20: 1616

4 Shimazu S, Kobayashi M, Okabayashi T et al. A case of GI Burkitt-like lymphoma. Gastrointest Endosc 2004; 60: 152 - 154

5 Dunleavy K, Wilson WH. How I treat HIVassociated lymphoma. Blood 2012; 119: $3245-3255$
Bibliography

DOI http://dx.doi.org/

10.1055/s-0034-1365818

Endoscopy 2014; 46: E322-E323

(c) Georg Thieme Verlag KG

Stuttgart · New York

ISSN 0013-726X

\section{Corresponding author}

Michael Sai Lai Sey, MD

Western University

London Health Sciences Centre

800 Commissioners Rd. E.

London, ON

N6A 5W9

Canada

Fax: +1-519-667-6820

Msey2@uwo.ca 